\title{
Primary tumours of the calcaneus (Review)
}

\author{
LITAO YAN $^{1 *}$, JUNWEI ZONG $^{1 *}$, JIN CHU $^{1}$, WENDONG WANG $^{1}$, MINGSHU LI $^{2}$, \\ XIANFENG WANG ${ }^{1}$, MINGZHI SONG ${ }^{1,3}$ and SHOUYU WANG ${ }^{1}$
}

\begin{abstract}
Departments of ${ }^{1}$ Orthopaedics and ${ }^{2}$ Ophthalmology, The First Affiliated Hospital of Dalian Medical University, Dalian, Liaoning 116011; ${ }^{3}$ Department of Orthopaedics, The Third Affiliated Hospital of Dalian Medical University, Dalian, Liaoning 116200, P.R. China
\end{abstract}

Received March 12, 2017; Accepted March 2, 2018

DOI: $10.3892 / \mathrm{ol} .2018 .8487$

\begin{abstract}
The calcaneus is a rare location for the occurrence and development of primary tumour types. Clinicians are unfamiliar with calcaneal tumour types, which may result in a delay in diagnosis or a missed diagnosis, resulting in unnecessary morbidity and amputation. Heel pain and localized swelling of the ankle are the most common symptoms. $\mathrm{X}$-ray is the first choice for a tentative diagnosis of a calcaneal tumour. The final diagnosis depends on a histological examination. The treatment of calcaneal tumour types varies depending on the Enneking system. The majority of patients with benign tumours heal, except for a few with a palindromia. For malignant tumours, the prognosis is comparatively poor, resulting in disability and a high rate of metastasis. This review describes the spectrum of calcaneal tumour types and specifically illustrates the epidemiology, symptomatology, imagology, histopathology and treatment options that may facilitate diagnosis and improve prognosis.
\end{abstract}

\section{Contents}

1. Introduction

2. Benign calcaneal tumour types

3. Malignant calcaneal tumour types

Correspondence to: Dr Mingzhi Song or Dr Shouyu Wang, Department of Orthopaedics, The First Affiliated Hospital of Dalian Medical University, 222 Zhong Shan Road, Dalian, Liaoning 116011, P.R. China

E-mail: smz10gb@163.com

E-mail:dmuwsy@sina.com

${ }^{*}$ Contributed equally

Abbreviations: CT, computed tomography; MRI, magnetic resonance imaging; BS, bone scan; ACP, acid phosphatase; CRP, C-reactive protein; ESR, erythrocyte sedimentation rate; $\mathrm{SBC}$, simple bone cysts; $\mathrm{ABC}$, aneurysmal bone cysts; $\mathrm{CMF}$, chondromyxoid fibroma

Key words: calcaneus, primary tumour, symptom, diagnosis, surgery
4. Discussion

5. Conclusion

\section{Introduction}

The foot is an uncommon location for osseous tumour types, which comprise $\sim 3 \%$ of all skeletal tumour types (1). In particular, primary malignancies located in the calcaneus are notably rare, accounting for $31 \%$ of benign and $35 \%$ of osseus tumor types in the foot. Current studies on calcaneus tumour types are limited, consisting mostly of individual case reports describing a single primary tumour of the calcaneus (2-4). Due to the rarity and lack of familiarity with calcaneal tumour types, delays in diagnosis and inadequate treatment are frequently reported (2). Furthermore, improper diagnosis and treatment even result in unnecessary amputation (1).

In the present review, currently reported types, clinical manifestations, radiological and histopathologic appearances, in addition to appropriate treatment options for a variety of benign and malignant tumour types in the calcaneus are presented. The purpose of the present review is to increase clinical awareness of primary tumour types in the calcaneus, as the stage of progression at which the tumour is at, at which it is identified, diagnosed and treated, is associated with the outcome and prognosis. To the best of our knowledge, the present review represents a relatively exhaustive review describing the known spectrum of tumour types of the calcaneus. Numerous other, more comprehensive reviews of the calcaneus are expected to be reported in the future.

\section{Benign calcaneal tumour types}

Simple bone cyst (SBC). SBCs are benign, fluid-containing skeletal lesions and are referred to as unicameral bone cysts or juvenile bone cysts (3). In a review of 258 patients with SBCs, the calcaneus was identified to be a relatively common site for the formation of SBCs, with a morbidity rate of $14 \%$ (4).

A majority of SBCs of the calcaneus were asymptomatic and diagnosed incidentally as a result of minor trauma to the foot or ankle (3-5). Pain is the major complaint in $\sim 44.4 \%$ of cases, and those who were middle aged experienced more severe pain (4). Pathological fracture is rare (3). On physical 
examination, patients demonstrated normal ankle and subtalar motion. There was no tenderness or instability in the ankle (6).

X-ray analysis (Fig. 1A) revealed a solitary bone cyst of the calcaneus that presented as a sharply demarcated radiolucent osteolysis surrounded by sclerotic borders $(4,6,7)$. The location of the cysts is usually the Ward's triangle of the calcaneus, anterolaterally to the posterior facet of the subtalar joint, where stresses are physiologically low (4,8). A cortical destruction may arise from a fracture (9). A computed tomography (CT) scan revealed a fluid-fluid level that represents the layering of fluids with different densities $(7,10)$. According to magnetic resonance imaging (MRI), there is a low signal intensity on the T1-weighted image, a high signal intensity (brighter compared with fat) on the T2-weighted image, and a thin rim, occasionally with septal enhancement, following the administration of intravenous contrast $(4-5,7,10,11)$. A bone scan (BS) is a normal part of diagnosis and may be a useful modality for the objective evaluation of symptomatic cysts and differential diagnoses, particularly for patients without fractures (5).

Macroscopically, a serous, fluid-filled cavity with strip-like bony prominences and a thin fibrous membrane may be identified during the surgery (7). Microscopically, haemosiderin deposits and fibrous tissues are a direct indicator of an SBC. Additionally, there should be no cytological atypia $(4,5,7)$. A cholesterol cleft is a common microscopic observation in calcaneal bone cysts, however, it is not detected in long bone cysts (5).

In the majority of cases, conservative management of calcaneal bone cysts is advocated due to the negligible symptoms that they produce and the rarity of complications including pathological fractures $(3,4)$. Surgical treatments (Enneking stage 1 to 2) have included endoscopic curettage and grafting $(8,12)$, curettage and bone grafting $(4,7,13)$, curettage, calcium sulphate pellet cement and autogenous grafting (4), multiple drilling (5), percutaneous cyst curettage and injection of demineralized bone powder and marrow $(9,11,14)$, minimal curettage combined with multiple drilling and continuous decompression through a cannulated screw (15), steroid injection (16) and tricalcium phosphate ceramic (17). Postoperative cases are almost asymptomatic with no recurrence excluding mild heel pain in two patients $(2,4,5,7,8)$.

Aneurysmal bone cysts $(A B C s)$. ABCs in the calcaneus are benign, expansive, locally destructive lesions that account for $1 \%$ of all primary bone tumour types (18-20). Of all $\mathrm{ABCs}, \sim 30-35 \%$ are present in association with another bone lesion including giant cell tumours, osteoblastomas and/or chondroblastomas $(18,19)$.

A majority of patients with ABC present complaints of heel pain subsequent to minor trauma, discomfort while walking and occasional swelling $(18,19,21)$. The heel pain may be chronic, worsening gradually following the trauma (19). Pathological fractures are rare but have been reported (18). During clinical examination, tender swelling may be observed without a local increase in temperature or lymph node swelling (21).

Upon radiographic examination, the lesion (Fig. 1B) is generally identified as a lytic, expansile lesion with an irregular or eccentric shape, thin sclerotic borders or septations (18). A CT may help establish an anatomic extent of the lesion, which is essential in order to delineate the fracture line and the scheme of surgical management (18). MRI clearly demonstrates an expansile and septate lesion with relatively well-defined margins that contain multiple fluid-fluid levels. The fluid-fluid levels may be best observed on the T2-weighted image with a varying signal intensity due to the chronicity of the associated haemorrhage $(18,19,22)$. A BS demonstrates increased uptake at the periphery in a number of cases (23).

Upon gross examination, fragments of multiple grey-brown or reddish-brown granular sections contain blood-filled cystic spaces (22). Histopathologic examination of the lesion reveals cavernous cavities of different dimensions containing fibroblasts, histiocytes and osteoclastic giant cells without any mitosis or atypia $(19,21,22)$.

The choice of $\mathrm{ABC}$ treatments ranges from wide resection of the cyst to curettage with bone grafting (Enneking stage 2) $(12,19)$. The use of adjuvants including cryotherapy, phenol, polymethyl methacrylate and irradiation is employed to remove an aggressive lesion (Enneking stage 3) (24). All ABCs of the calcaneus have been observed to heal well with no local pain and recurrence during a follow-up period of $>5$ years $(18,19,21-23)$. Due to the risk of recurrence associated particularly with chondroblastomas, 6 month CT scans are recommended for the first two postoperative years $(19,25)$.

Osteoid osteoma $(\mathrm{OO})$. $\mathrm{OO}$ is a relatively common benign tumour that is more frequently observed in the younger population, aged $7-25$ years $(1,26)$. It has a higher incidence in the male population, which accounts for $74 \%$ of all cases (27).

Chronic nocturnal pain and swelling are the main complaints of patients with $\mathrm{OO}$ and are usually located in the talocalcaneal joint, and may be characteristically relieved by non-steroidal anti-inflammatory drugs (26). Physical examinations are non-specific and may reveal joint effusion, local temperature rise, tenderness, stiffness and muscle atrophy $(26,27)$. Occasionally the patient is unable to flex the plantar ankle as a result of severe pain $(28,29)$.

Inflammatory reactions in the blood and marker level abnormalities are frequently observed in reported cases $(26,27,30)$. $\mathrm{X}$-ray only analysis reveals surrounding sclerosis of the calcaneus, which potentially results in misdiagnosis of a SBC (26). $\mathrm{CT}$ is a superior method for demonstrating a well-defined nidus, which is a round or oval smoothly marginated lytic lesion with central mineralization $(26,27)$. MRI reveals low signal intensity on the T1-weighted image and a variable signal on the T2-weighted image due to adjacent inflammation or oedema (29-32). BS is a meaningful method for delineating symptomatic areas (33).

Histologically, the nidus consists of osteoblasts and osteoclasts surrounded by giant cells and vascular and fibrous connective tissue (27). A number of studies have suggested that $\mathrm{OO}$ may be managed conservatively using anti-inflammatory medications $(1,28,30)$. However, open surgery with or without bone grafting (Enneking stage 1-2) is a preferential option for patients who are insensitive to conservative treatment (29). Previously, minimally invasive techniques, including percutaneous CT-guided resection, radiofrequency ablation and laser photocoagulation, have undergone remarkable progress in decreasing the risk of 

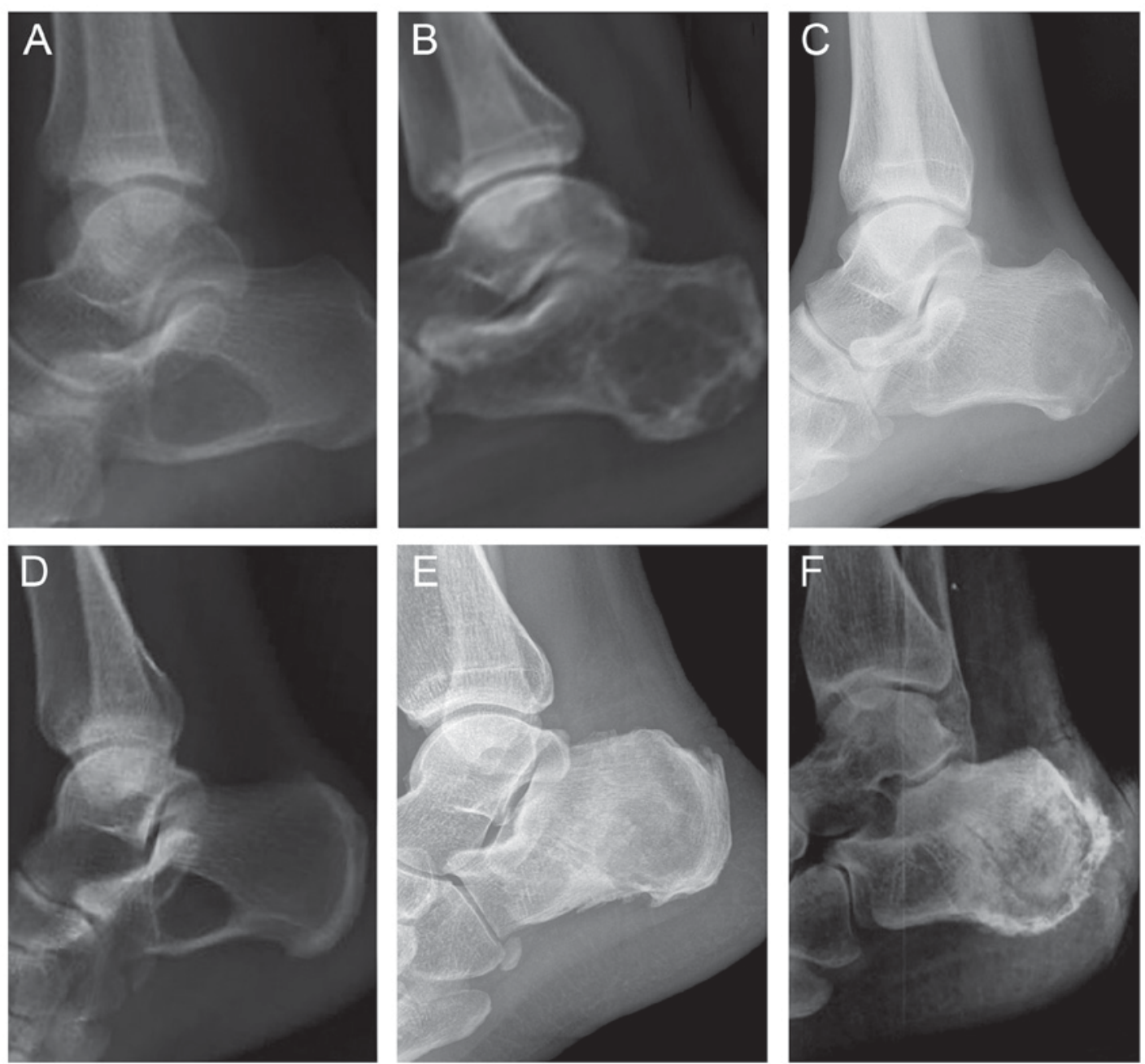

Figure 1. Lateral x-ray of a number of different calcaneal tumour types. (A) Simple bone cysts of the calcaneus. A solitary, sharply demarcated radiolucent osteolysis may be observed in the calcaneus, without a pathologic fracture. (B) Aneurysmal bone cysts of the calcaneus. The lesion is generally identified as a lytic, expansile lesion with an eccentric shape and septations. (C) Chondroblastoma of the calcaneus. The lesion is located in the posterior calcaneus, which is a lytic expansile mass with a sclerotic margin. (D) Intraosseous lipomas of the calcaneus. A well-circumscribed lytic lesion is located at the base of the calcaneus neck in the region of the Ward's triangle. (E) Chondromyxoid fibroma of the calcaneus. The lesion demonstrates a large lytic lesion with sclerotic margins and 'soap bubble' appearance. (F) Chondrosarcoma of the calcaneus. The lesion shows a destructive, expansive and pathologic fracture with calcification of the soft tissues.

bone architectural changes and fractures that result from open surgical excision (32,34-36).

Osteochondroma. Osteochondroma in the calcaneus is rare, constituting $10 \%$ of all osteochondromas associated with hand and foot bones (37). It is exclusively identified in patients $<20$ years-old, which indicates a malignant transformation in adults $(1,37,38)$.

Clinically, patients may initially present with an enlarging mass with a painless deformity (38). Noticeable symptoms arise with the appearance of progressive pain, swelling and stiffness, which are attributed to fractures, malignant transformation and a low proportion of subcutaneous tissue (38-41). Upon physical examination, a stiff, firm and painful nodular mass may be palpated (37-39). The motion of the ankle is observed to be normal but presents a mildly painful active flexion $(40,42)$. Routine laboratory test results are within the normal range (37-42).

On radiographs, the X-ray generally reveals a solitary bone prominence from the bone surface that is pedunculated or sessile (41). The hyaline cartilage cap is not apparent on $\mathrm{X}$-ray, but it is present at a low attenuation on CT (11). The three-dimensional imaging features of CT provide accurate information about the dimensions of the lesion $(38,39)$. MRI is the best technique with which to evaluate the hyaline cartilage cap, which presents a low signal intensity in T1and T2-weighted images (38-40). A thickness of the hyaline cartilage cap $>1.5 \mathrm{~cm}$ suggests a malignant transformation of the chondrosarcoma $(38,40)$, and a BS allows an optimal correlation with the degree of endochondral bone formation (39).

The pathologic anatomy of the lesion is a polypoid soft tissue covered with a cartilage cap (43). Biopsies reveal a spongy bone covered with a hyaline cartilage cap, in accordance with the characteristics of osteochondroma (43).

Treatment is usually not necessary for patients with asymptomatic lesions (38). Surgical removal is considered for aggressive growth subsequent to skeletal maturity, which indicates malignant transformation (39-41). A marginal resection (Enneking stage 1-2) is adequate and indicates a low rate of 
recurrence (39-41,43-45). The key point to avoid recurrence is the complete excision of the lesion (45).

Chondroblastoma. Chondroblastoma is a rare chondroid tumour, accounting for $4.5 \%$ of all bone tumour types and $2.8 \%$ of all calcaneal tumour types (46). There is a clear male predominance with an incidence ratio of 5:1 (46).

Local pain, soft tissue swelling and tenderness are the main complaints of patients with chondroblastoma $(46,47)$. A physical examination mostly involves oedema and painful palpation of the heel in addition to joint dysfunction of the ankle (47). All routine laboratory tests produce results that are within normal ranges (48).

Plain radiographs demonstrate an osteolytic lesion (Fig. 1C) with a sclerotic margin or tiny, stippled calcifications. The fracture line appears in patients with a pathological fracture (48). CT demonstrates a well-defined osteolytic lesion and intracortical lucency (49). MRI for the chondroblastoma reveals an irregular, expansive lesion and fluid-fluid levels. There is a heterogeneous, low to intermediate signal intensity on the T1- and T2-weighted image. All lesional and perilesional regions demonstrated diffuse enhancement following contrast administration (49,50). Furthermore, bone marrow oedema and soft tissue oedema may be observed in the case of a pathologic fracture (48).

The gross appearance of the excised lesion reveals a soft, grey-brown, multiloculated cystic lesion with bone fragments and a haemorrhagic mass $(47,50)$. Histologically, the tumour is composed of proliferating, polygonal chondroblasts, small mononuclear cells, multinucleated giant cells and calcifications (48).

Surgical treatment is the preferred choice for chondroblastoma, including simple curettage with bone grafting in addition to endoscopic curettage without bone grafting (Enneking stage 2) (47,49-51). The latter is a more effective treatment for chondroblastoma with a secondary ABC (49). However, recurrence is highly attributed to the pattern of simple curettage, inadequate resection and the association with secondary ABCs $(46,48)$.

Intraosseous lipoma. Intraosseous lipomas are rare tumour types, constituting $0.1 \%$ of all benign bone tumour types. Furthermore, only $8 \%$ of these tumour types are located in the calcaneus $(52,53)$. The tumour is often revealed in patients ranging in age from 30-60 years $(52,53)$.

Of all cases, $\sim 40 \%$ of cases are identified incidentally. However, in symptomatic cases, pain is the most common symptom, particularly following a strenuous walk $(52,54)$. The pain may be relieved with aspirin and sufficient rest (55). Upon physical examination, an antalgic gait pattern may be present during walking $(54,55)$. Pain in response to palpation surrounding the lesion is consistently observed with or without swelling (52). There are usually no unique laboratory results (52-55).

X-ray of the intraosseous lipoma (Fig. 1D) reveals a well-circumscribed lytic lesion with central, single or ring-like calcifications, a majority of which are located at the base of the calcaneus neck in the region of the Ward's triangle. CT provides a higher-grade image, including the anatomic location, size, extent and potential pathologic fracture. MRI demonstrates high signal intensity on the T1-weighted and T2-weighted image, which is more accurate in terms of the image of the bone marrow and soft tissue (52-58).

The gross appearance of the excised lesion reveals a yellow, friable fatty tissue with fragments of bone (54). Histologic examination presents fat cells surrounded by necrosis and calcification, which are interspersed with areas of haemorrhage and bony trabeculae $(52,54,55)$.

Asymptomatic lesions (Enneking stage 1) may be treated conservatively as they are consistently located in the region of the Ward's triangle, which is a non-weight-bearing area of trabecular rarefaction (58). However, lesions (Enneking stage 2) that are symptomatic, oversized and prone to pathological fracture are indicated for surgical treatment $(57,58)$. Curettage and autologous bone grafting is an easy and effective operation for intraosseous lipoma, followed by a long-term non-weight bearing period (52-55). Previously, endoscopically assisted tumour curettage followed by filling of the bone defect with $\alpha$ - or $\beta$-tricalcium phosphate has been demonstrated to be a less invasive method that allows patients to walk normally subsequent to wound healing $(59,60)$. In a number of reported cases, there has been no recurrence or complications following surgical treatment (52-63).

Giant cell tumour (GCT). GCT of the calcaneus is a benign neoplasm that makes up $1.2 \%$ in all cases of calcaneal tumours and exhibits high recurrence and potentially aggressive features (64-66). It is most commonly observed in patients who are 30-40 years old (64).

Clinically, heel pain and swelling are the primary complaints in patients with calcaneal GCT $(64,65)$. On physical examination, a tender and prominent hard swelling is palpated. The range of ankle joint motion is normal (64-67). Serum biochemistry is within normal limits, barring other unassociated systemic conditions (68).

Radiographically, there is an expansile or eccentric lytic lesion with a non-sclerotic margin, which may extend near the articular surface $(65,68)$. A CT scan may confirm the marked expansion of the calcaneus (67). However, aggressive features may additionally be identified, including cortical expansion or destruction of the soft tissue component (65). MRI reveals low signal intensity on the T1-weighted image and a high signal intensity on the T2-weighted image (69). The histological features consist of numerous multinucleated giant cells. Spindle cells and ABC features may be present in certain areas $(65,69)$.

Traditionally, curettage is the primary mode of treatment, accompanied by phenol, alcohol or cement to decrease recurrence (Enneking stage 2) (66). In cases of recurrence and aggressive GCTs (Enneking stage 3), limb salvage surgery consisting of a wide excision of total calcaneoctomy, bone allograft reconstruction and soft tissue coverage with a sural flap, are considered superior to amputation (65).

Chondromyxoid fibroma $(C M F)$. CMF of the calcaneus is a rare benign primary bone tumour composed of immature myxoid mesenchymal and cartilaginous tissue, making up $\sim 7 \%$ of all cases (70-73).

The slow-growing CMF often results in a delay in diagnosis, particularly in patients which lack symptoms $(70,71)$. The chief 
complaint in patients is chronic heel pain with a slow-growing mass, with a limp and limited range of ankle motion $(71,72)$. Physical examination observations are unremarkable, except for a palpable, hard and non-mobile protrusion from the lesion of the calcaneus (71). Laboratory investigations do not reveal any abnormal results (71-73).

The classic radiographic evaluation of the calcaneus (Fig. 1E) is a well-defined, geographic lesion with thin, sclerotic margins associated with septation and lobulation. CT may be used to clearly define the expanded or thin cortex in addition to the cortical integrity $(71,72)$. MRI is useful to characterize the tumour and to assess the tumour extent for preoperative planning (71). It reveals lesions as a low signal intensity on the T1-weighted image and a prominent high signal intensity on the T2-weighted image owing to the chondroid and myxoid composition (72-74). Peritumoral oedema of the marrow is seldom present, indicating a more aggressive tumour (71).

The characteristic gross appearance of the lesion is a grey or white multilobulated mass composed of a fibro-gelatinous substance with pieces of cartilaginous material $(71,72)$. Intralesional haemorrhage and cystic degeneration may additionally be identified in a number of cases (71). Histologic examination indicates variable proportions of cartilaginous, myxoid and fibroid tissue. The immunohistochemical stain for $\mathrm{S}-100$ is focally positive $(71,72)$.

Certain patients with CMF (Enneking stage 2) may be treated using simple curettage, however, this technique has been reported to retain tumour cells and is responsible for recurrence $(71,73)$. Thus, the combination of simple curettage, curettage with dental bur augmentation, block resection or even amputation have been demonstrated to be effective $(71,73,74)$. Patients should be followed up for a minimum of 3 years to monitor signs of recurrence (71). Routinely, a short leg cast for 6 weeks in addition to physical therapy are essential (72).

Other benign calcaneal tumour types. Other reported benign calcaneal tumour types include desmoplastic fibroma, osteoblastoma, ganglion, benign fibrous histiocytoma, primary xanthoma and intraosseous spindle cell haemangioma (75-87). Additional details cannot be obtained due to a limited number of case reports. Known details are provided in Table I.

\section{Malignant calcaneal tumour types}

Osteosarcoma. Osteosarcoma is the most common non-haemopoietic primary malignant neoplasm of bone (88). The calcaneal location of osteosarcoma is rare, accounting for only $1 \%$ of all osteosarcoma (89). Younger people (between 10 and 30 years old) are typically affected, with a peak in the second decade of life $(89,90)$.

Progressively worsening pain and swelling in the affected ankle joint are major complaints in patients with osteosarcoma in the calcaneus $(88,90,91)$. During physical examination, the swelling is tender, immobile and the mobility of the joint is restricted $(88,90)$. A prior history of trauma has been noted in multiple cases $(89,92)$.

In the case of a small cell osteosarcoma in the calcaneus, laboratory tests reveal an increase in the erythrocyte sedimentation rate (ESR) and in C-reactive protein (CRP) levels (91).
Radiograph and CT of the calcaneus reveal a sunburst appearance with a dense sclerotic lesion, cortical destruction and extraosseous expansion $(88,90,93)$. A majority of cases consist of a mixture of lysis, sclerosis and rarefaction (88). CT reveals soft tissue extension and a large osteolytic lesion with cortical thinning/breakthrough (90). MRI was performed for preoperative staging in addition to confirming the presence of surrounding soft tissue infiltration, presenting an intermediate intensity on the T1-weighted image due to sclerotic bone formation and a high signal intensity on the T2-weighted image (88). $\mathrm{CT}$ of the chest, abdomen and pelvis ought to be performed to rule out metastatic disease at the time of diagnosis (88).

The lesion was observed as a tan-white, yellow, heterogeneous, smooth and firm mass located in the body of the calcaneus $(88,91)$. The pathological image presented a diffuse proliferation of the spindle and atypical cells characterized by nests or cords encompassed by abundant osteoid deposits $(88,90,93,94)$. Sheets of pleomorphic osteoblasts, mitotic features and osteoid formation may additionally be observed $(88,90)$.

Prior to and following surgery, all patients have been reported to accept chemotherapy (88-93). The optional surgery of the calcaneal osteosarcoma varies depending on the tumour stage (89). Patients (Enneking stage IIB) who have undergone below-knee amputation have a satisfactory form of treatment, with no evidence of local recurrence in those who survive $>2$ years (89). Furthermore, a calcaneal prosthetic replacement, which is beneficial for functional consequences, may be an appropriate treatment for special intramedullary tumours (stage IIA) that respond well to preoperative chemotherapy $(91,93)$. Two patients presented with metastatic disease $(88,90)$.

Primary osseous lymphoma. The calcaneus is a rare site of primary osseous lymphoma that represents $\sim 1.2 \%$ of 246 cases in clinical research (95).

The symptoms vary from mild non-specific pain to soft tissue swelling, often with a lack of constitutional symptoms (96-98). A number of cases may be accompanied by a pathological fracture $(95,96,98)$. A physical examination of the affected hind foot may reveal non-pitting oedema, reddening and tenderness $(97,99)$. Laboratory tests all produce results that are within normal limits (100).

Radiographs reveal a mixture of osteolysis and sclerotic lesions of the calcaneus, which produce a 'moth-eaten' and patchy appearance $(96-98,101)$. Periosteal reaction, pathologic fracture and soft tissue involvement may additionally be observed $(99,100)$. The MRI examination presents a large, lobulated, expansile lesion arising from the calcaneus with a low signal intensity on the T1-weighted image, raising suspicion of neoplastic disease $(97,99,100)$. On a gallium scan, increased radiotracer uptake has been noted in the location of the lesion (98).

Intraoperative observation reveals a suet-like tissue in a patient with a T-cell lymphoma (97). Histological examination most often reveals a large number of lymphoid elements with hyperchromatic large nuclei, abundant cytoplasm, and prominent nucleoli (98). Immunophenotyping and histochemical stains for cluster of differentiation (CD)20 and L26 (a pan-B-cell marker) are positive in cases of B-cell lymphoma $(98,99)$. 
At present, complete excision of the lesion alone is usually not curative $(88,89)$. In cases without metastasis (Enneking stage IIB), the patient is treated with a multiple chemotherapy regime. Although patients experience anaemia and fatigue with chemotherapy, it is effective to be disease free for $>5$ years (98). Radiation therapy is recommended following chemotherapy $(96-98,101)$. Primary osseous lymphoma has provided a good prognosis, except in one patient (Enneking stage III) with a recurrent lesion in the contralateral distal tibia (100). A majority of patients respond well to the treatment and present without local or metastatic disease during long-term follow-up $(96-98,101)$.

Chondrosarcoma. Chondrosarcoma is one of the most common malignant tumour types following osteosarcoma and myeloma, with $\sim 3 \%$ of all chondrosarcoma present in the foot (1). In a report of 75 cases of chondrosarcomas in the foot, $28 \%$ were present in the calcaneus (102).

Chondrosarcoma has an indolent natural history, ranging from 8 months to 36 years (102). Clinically, chondrosarcoma is characterized by insidious, gradual and progressive pain (103). Upon physical examination, the swelling is diffuse, mildly tender to palpation, and occasionally accompanied by a local increase in temperature $(103,104)$.

Common radiographic features (Fig. 1F) include deep endosteal scalloping with bone expansion, cortical destruction, endosteal erosion, matrix calcification, periosteal reaction and pathologic fracture (102-107). CT of the calcaneus has been more accurate in the detection of soft tissue extension, calcification and cortical involvement (105). Using MRI, a well-defined lobulated mass with a low signal intensity may be observed on the T1-weighted image and a high signal intensity on the T2-weighted image with multiple septations, reflecting the high water content of this cartilaginous neoplasm $(106,107)$. In the contrast-enhanced image, rings and arcs may be observed as a typical lobulated growth pattern (107). On BSs, there is increased tracer uptake in the lesion. BS and chest X-ray/CT must be performed routinely to rule out metastasis even in the absence of clinical symptoms (105).

Macroscopically, the tumour tissue presents with a straw-yellow colour (103). Microscopy may reveal numerous pleomorphic chondrocytes with hypercellularity and cytologic atypia. An abundant foamy to clear cytoplasm is a feature of clear cell chondrosarcoma (105). With the use of immunohistochemistry, the tumour cells are positive for S-100 proteins and negative for cytokeratin and CD68 (104-106).

Surgery ought to be a top priority for the treatment of chondrosarcoma. Wide surgical resection or amputation remains regarded as a mainstay method, while simple curettage or local excision is not recommended due to recurrence (102-106). If the tumour (Enneking stage IIA) is restricted to a bone that may be completely removed with an appropriate amount of soft tissue, a wide excision is recommended and usually requires at least a $5 \mathrm{~cm}$ safety margin $(102,103,106,107)$. For patients with a stage IIB tumour, amputation is recommended and believed to result in an improved disease-free survival rate (102-107). Although chemotherapy and radiotherapy have no effect in chondrosarcoma, they are administered as a palliative therapy in the case (stage III) of metastatic and inoperable disease $(103,105)$.

Recurrence and metastasis of chondrosarcoma constituted nearly $50 \%$ of all patients in one previous study (102). Metastasis typically occurs to lungs and proximal bones (103-105). Owing to the propensity for recurrence and metastasis, all patients with chondrosarcoma of the calcaneus require long-term follow-up (102-104).

Ewing's sarcoma. Ewing's sarcoma of the calcaneus is a primary, aggressive malignant tumour, of which $>50 \%$ of all cases occur in the foot (108).

Local pain and swelling of the ankle are the primary symptoms of patients, in addition to a limp foot and erythema $(108,109)$. Constitutional symptoms, including fever and weight loss are observed in a number of cases (108). Upon examination, the swelling is always extensive around the heel, resulting in stretched and shiny skin in addition to visibly dilated subcutaneous veins $(108,110)$.

Blood laboratory tests revealed elevated ESR, acid phosphatase (ACP) and leucocytosis levels accompanied by mild or moderate anaemia (108-110). X-ray revealed a 'moth-eaten' type of destruction with an aggressive periosteal reaction and cortical violation in the calcaneus (109). CT visibly demonstrated a classical 'sun-ray' or 'onion-peel' appearance of the periosteal reaction, which may additionally be parallel, speculated or mixed (109-111). MRI presented a low signal intensity on the T1-weighted image and a high signal intensity on the T2-weighted image, which is unable to adequately distinguish the tumour from necrosis. Therefore, the enhancement pattern following administration of contrast medium is competent for the differentiation between oedema and haemorrhage (111). BSs reveal an increased area of uptake in the region of the tumour. Chest radiography/CT is necessary in order to detect bone metastases (110-112).

A biopsy of the tumour with histopathological analysis revealed a malignant small round-cell tumour with little or no intercellular stroma (109-112). CD99 and periodic acid-Schiff were immunohistochemically positive $(109,112)$.

A combination of surgical resection, multidrug chemotherapy and radiotherapy are particularly applicable in comparison with surgery alone (108-112). Multidrug chemotherapy increases the overall survival rate of patients (Enneking stage IIB to III) with Ewing's sarcoma by reducing the risk of metastases, whereas surgery combined with preoperative chemotherapy reduces the risk of local recurrence (108). The prognosis of this tumour is the worst among any primary sarcoma known to metastasize to the lungs and other bones including the tibia, fibula or tarsal bone (109-111). Patients with localized Ewing's sarcoma have a higher probability of disease-free prognosis (108).

Other malignant calcaneal tumour types. Other sporadic malignant cases that have been ever reported, including malignant fibrous histiocytoma, multiple myeloma, haemangioendothelioma, fibrosarcoma, malignant peripheral nerve sheath tumour, primary epithelioid angiosarcoma, primitive neuroectodermal tumour, and adamantinoma, are summarized in Table I (113-120).

\section{Discussion}

The calcaneus is the largest tarsal bone of the foot in humans. It develops from an ossification similar to that of the epiphysis 


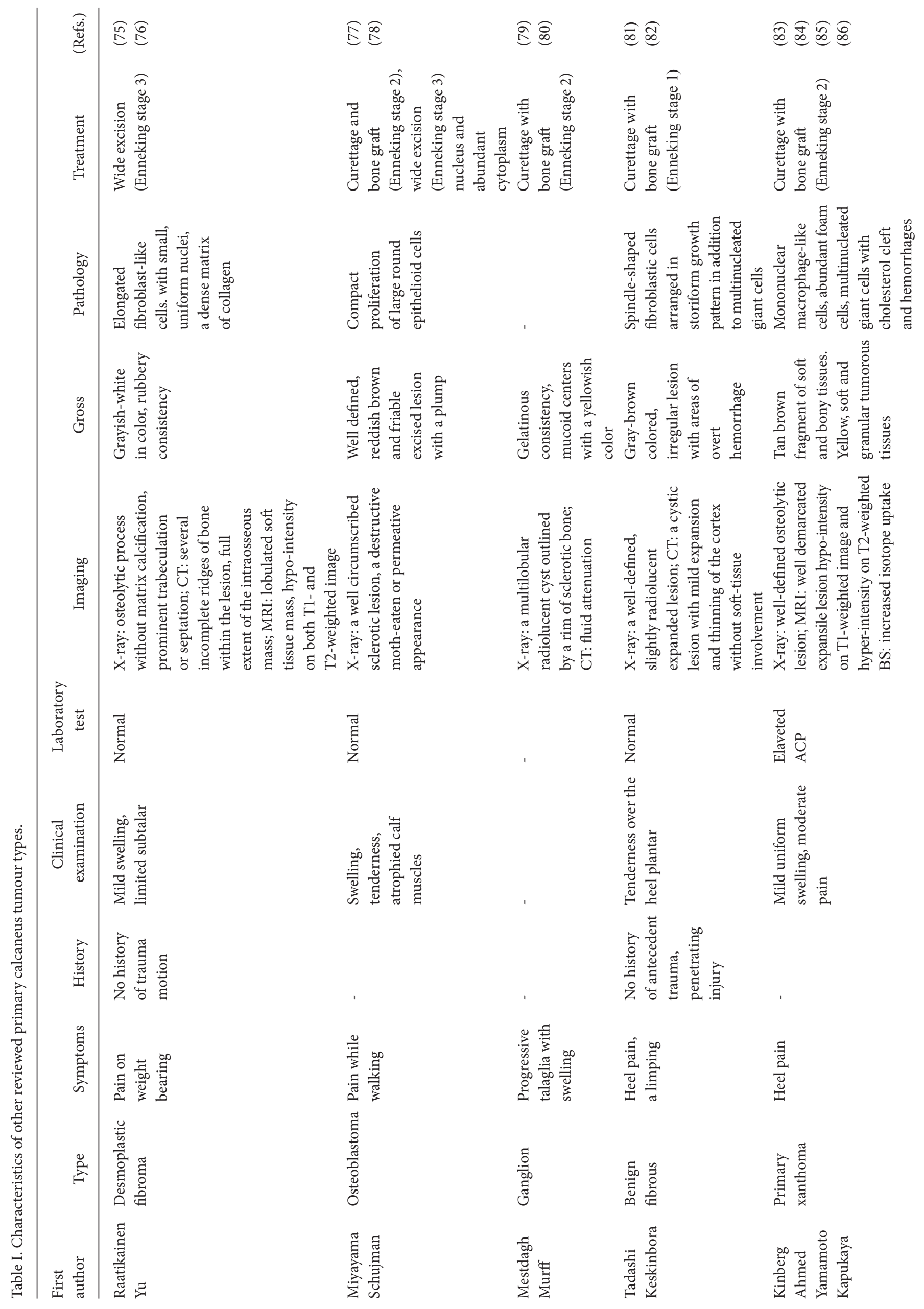




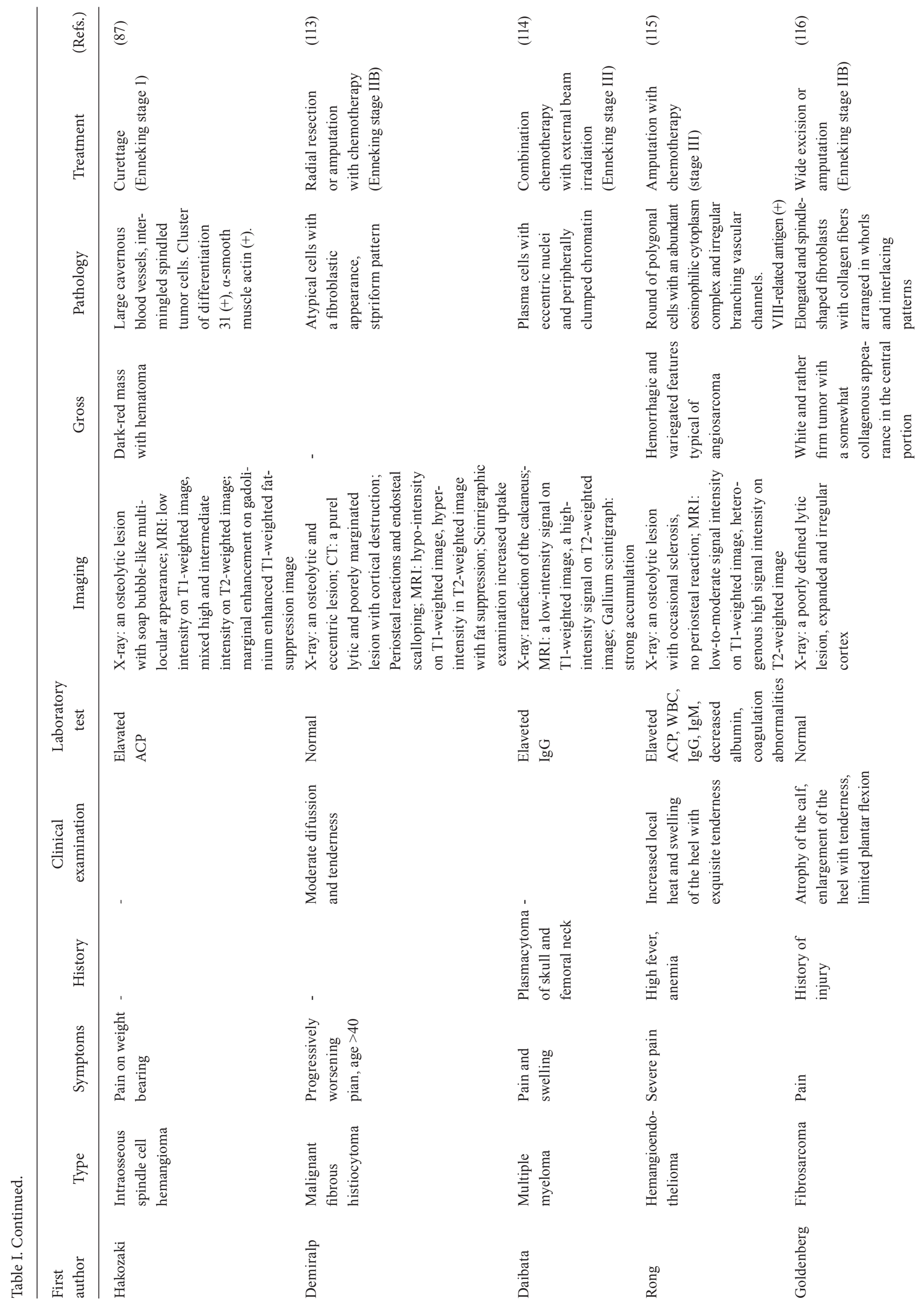




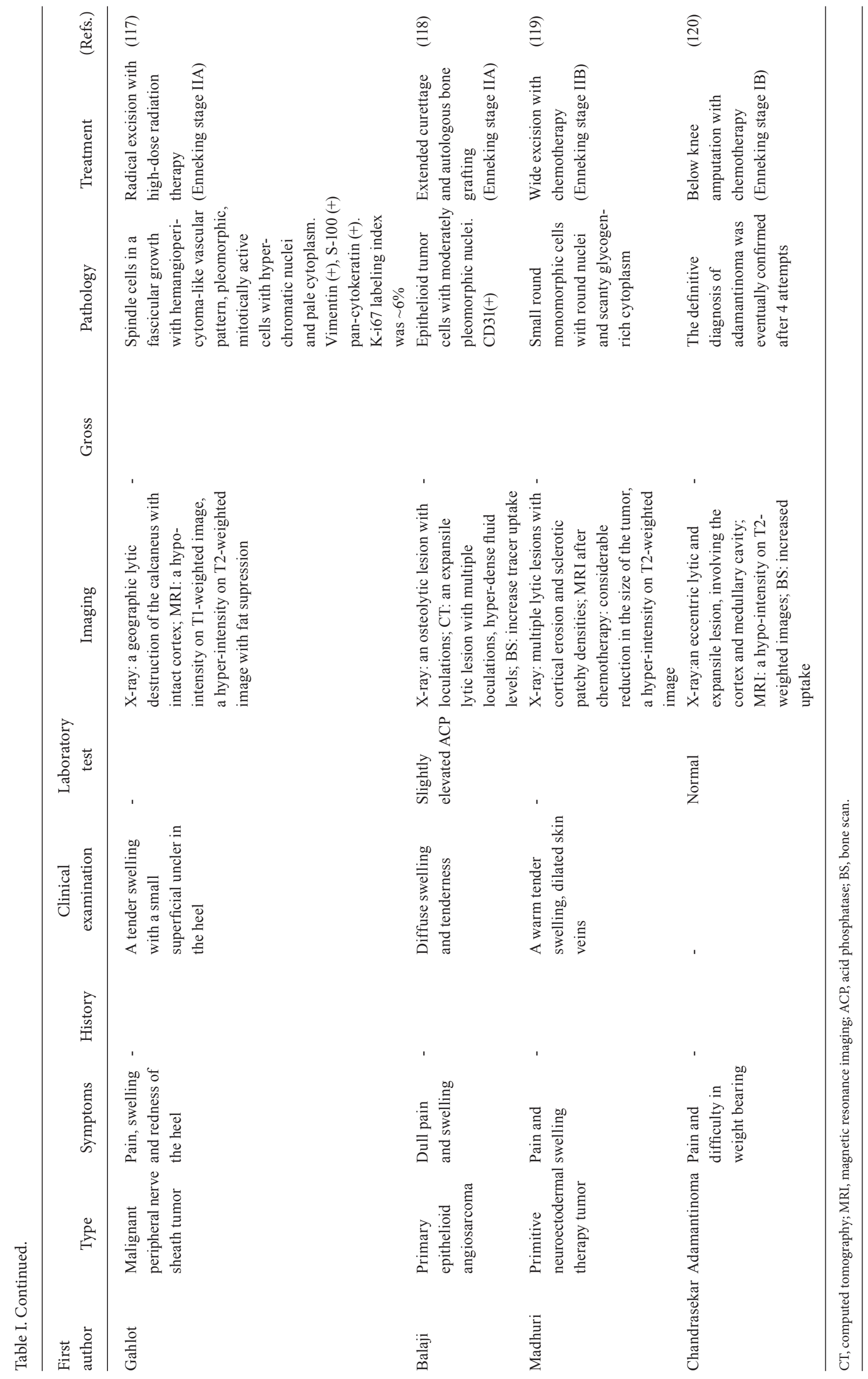


of a long bone, during the 4th-7th week of foetal development (1). Therefore, the calcaneus is a potential location for an osseous tumour, occupying the second most common site in the foot following metatarsals (1). Previous studies on calcaneal tumour types are limited and dominated by case reports and reviews. Consequently, a substantial number of clinicians are unfamiliar with calcaneal tumour types, resulting in a delay in diagnosis or unnecessary treatment $(2,61)$. Thus, early diagnosis and management are essential to improve outcomes, particularly in high-grade malignancies.

A majority of benign tumour types of the calcaneus are asymptomatic, including a SBC, intraosseous lipoma and osteochondroma $(4,44,45)$. They are diagnosed incidentally as a result of minor trauma to the foot or ankle $(3,22)$. The most common complaint of these symptomatic patients is an intermittent or constant heel pain over the duration of a few months to years $(22,55,57)$. For benign tumour types, the pain often occurs at night and may be relieved temporarily by nonsteroidal anti-inflammatory drugs with a weakening effect due to tolerance $(61,64,65)$. A rapidly growing pain may result from a malignant tumour (2). Pathological fracture following minor trauma consistently results in sudden pain due to substantial cortical disruption of the calcaneus $(1,57)$. Swelling is a common secondary symptom of active and aggressive lesions $(4,5,89,101)$.

Upon physical examination, patients who suffer from severe pain and swelling may experience difficulty in weight bearing, presenting an antalgic gait pattern $(64,65)$. Motion of the subtalar, midtarsal and ankle joints may be limited or painful only if the tumour is in close proximity to the joint (121). Certain symptoms including atrophy of the calf, enlargement of the heel and visible dilated subcutaneous veins may additionally be observed $(1,2,10)$. Upon palpation, a soft or hard mass may be detected in the region surrounding the lesion. Furthermore, local redness, effusion, heat or even superficial ulcers is a specific sign of a malignant and aggressive tumour $(10,121,122)$. A vibratory exam may elicit pain, particularly if the tumour involves cortical or subchondral bone (22). In general, symptoms and physical examinations are nonspecific, potentially resulting in misdiagnosis including plantar fasciitis, chronic ankle sprain, os-trigonum syndrome, calcaneal apophysitis, retained foreign bodies and fractures $(2,26,30,32,64,121)$. Therefore, a comprehensive history and physical examination should be completed for any patient with pain and swelling of the foot to obviate the delay in diagnosis and allow an early and accurate diagnosis. It is additionally important to identify whether any other sites are involved $(1,2)$.

Laboratory tests of calcaneal tumours remain insufficient in previous studies $(1,2)$. The main tests conducted include testing the levels of ESR, CRP, ACP, leucocytosis, coagulation tests and protein electrophoresis $(3,4,18,19)$. Although the results are usually within normal limits in a majority of cases, an elevated ACP may be observed in tumours including Ewing's sarcoma, primary xanthoma and intraosseous spindle cell haemangioma (87,108-110). An increased level of immunoglobulin may be detected in multiple myeloma (114). However, differential diagnoses cannot depend exclusively on laboratory tests (1).

$\mathrm{X}$-ray is the first choice for the detection of the lesion and to make a tentative diagnosis (57). Although the calcaneus differs from other long bones in terms of shape, dimension and trabecular bone architecture, radiographs of the calcaneal tumour are similar to those of long bones in terms of imaging characteristics $(1,2)$. It is essential to carefully examine imaging changes, including the extent, location, calcification, sclerosis cortical violation, permeative destruction, periosteal reaction, pathological fracture and soft tissue mass of the tumour $(10,57)$. A well-defined osteolytic area with a sharp and sclerotic margin is mainly presented in benign tumour types (121). For malignant and aggressive tumour types, a 'moth-eaten' (multiple erosions with coalescence into larger lesions) or permeative (multiple, small lytic areas) pattern are typical $(100,102)$. Slow-growing, low-grade tumours cause reactive thickening of the cortex, whilst high-grade neoplasms that are more aggressive destroy the cortex. Radiographs retain the initial imaging modality, providing valuable information regarding the morphology and biological behaviour of calcaneal tumours $(1,57)$. However, when compared with CT and MRI, there remains lack of information for formulating a reasonable differential diagnosis (45). CT is an excellent auxiliary method for providing determinations of morphological modifications $(27,34)$. In particular, MRI has a unique advantage for defining the soft tissue extent and stage of the tumour and helping to implement surgical resection in addition to gauging the risk of fracture $(16,102,106)$. Among several cases, increased uptake in the lesion may be observed in a BS, which is useful in identifying active processes and multiple lesions $(1,2,89)$. CT of the chest and abdomen is an essential prerequisite for detecting bone metastases $(97,98,100)$.

Histological examination is the gold standard for the diagnosis of a majority of calcaneal tumour types, which remains in accordance with their intrinsic pathological characteristics $(1,2)$. There are three types of biopsies in reported reviews, as follows: i) For a benign calcaneal tumour, the excisional biopsy means removing the tumour entirely followed by the tumour being sent to the pathologist. It is not recommended for those with any doubt about the diagnosis. ii) An open incisional biopsy is used to remove a piece of the specimen from the tumour and has been validated as the most accurate. iii) A needle biopsy is safer and less traumatic compared with an open incisional biopsy, with a reduced potential of contamination and complications $(1,122)$. However, there is a risk of overlooking problematic cells, which may result in a false negative result. If the diagnosis is uncertain, a second or multiple biopsies are essential (21). In fact, due to a lack of adequate clinical and radiographic information, an incorrect diagnosis may be made by the pathologist based only on microscopic features. For instance, an ABC may be misdiagnosed as an osteosarcoma due to the similar histological features (25). In this circumstance, a combined diagnosis based on radiology, pathology and surgery, following a thorough review of all available information, is imperative $(10,121,122)$.

Upon treatment of benign tumour types, conservative treatment of asymptomatic patients (including those with SBC and $\mathrm{OO}$ ) is advocated due to the negligible symptoms that they produce and the rarity of complications including pathological fractures $(3,33)$. The patient must be followed-up on a regular basis to observe whether the lesion increases or decreases in size. If persistent heel pain disturbs the patient's daily life or there is a risk of impending fracture, surgical treatment is the only choice $(4,10)$. In the present study, the Enneking system 
Table II. Summary of the classification and treatment.

\begin{tabular}{llll}
\hline Stage & \multicolumn{1}{c}{ Characteristics } & \multicolumn{1}{c}{ Surgery } & \multicolumn{1}{c}{ Examples } \\
\hline 1 & Inactive & Curettage & SBC, Osteochondroma \\
2 & Inactive & Marginal resection & SBC, Osteochondroma \\
3 & Aggressive, destructive & Wide resection & Giant cell tumor ABC \\
IA & Low-grade intracompartmental & (involvement of joint, vessel and nerve) & Adamantinoma \\
IB & Low-grade extracompartmental & Radical resection or calcaneal prosthetic & Chondrosarcoma, Osteosarcoma \\
IIA & High-grade intracompartmental & Below-knee amputation with chemotherapy \\
Combination chemotherapy with external & beam irradiation & Chondrosarcoma, Osteosarcoma \\
IIB & High-grade extracompartmental & Multiple Myeloma hemangioendothelioma \\
III & Low-and High-grade lesions & with metastases respectively &
\end{tabular}

was used in order to formulate a relatively safe and reasonable operation plan (Table II) $(1,10,12)$. Curettage with bone grafting and resection are major surgical treatment options for patients with a benign tumour of the calcaneus (123). In comparison with open curettage with more soft tissue dissection, there has been considerable development of endoscopic resection, which may diminish the risk of iatrogenic sural nerve damage and accelerate superficial wound healing (124). For malignant tumours of the calcaneus, radical resection (including limb salvaging) and amputation should be thoroughly assessed in terms of local tumour appearance, histological grade and physical disabilities (including antalgic gait pattern) (88-90,97,98,107-110). Although amputation is considered the most common option in order to achieve adequate local control of a primary malignant bone tumour, phantom pain is highly prevalent among patients with lower limb amputation due to of the loss of major nerves (125). With the development of effective neoadjuvant chemotherapy, limb salvage surgery has become a superior treatment for primary calcaneal malignancy (126). However, reconstruction following radical resection remains a challenge to surgeons in terms of preservation of function as well as quality of life $(119,126)$. Fortunately, biological reconstruction using pedicled osteocutaneous fibular flaps has been confirmed to be a successful limb salvage procedure (126). Furthermore, a calcaneal prosthetic replacement may be appropriate for special intramedullary tumour types that respond positively to preoperative chemotherapy $(91,93)$. In all cases that result in an unstable calcaneal structure, the lower limb is immobilized in a short leg cast for 6 weeks followed by resumption of weight bearing $(1,10,126)$. Physical therapy is recommended following the radiographical appearance of signs of bone healing. Follow-up reports on the prognosis of calcaneal tumours are scarce (10). A majority of patients with benign tumour types heal, excluding a few cases with a palindromia $(1,121)$. For malignant tumour types, the prognosis is relatively poor, resulting disability and a high rate of metastasis $(1,98,126)$.

\section{Conclusion}

The calcaneus is a rare location for the occurrence and development a primary tumour (1). Heel pain and localized swelling of the ankle are the most common presenting symptoms in previous reports of calcaneal tumour types, which are often misdiagnosed as soft tissue injuries. A calcaneal tumour ought to be considered when a patient presents with persistent or severe pain, swelling or the absence of trauma (10). A tentative diagnosis of a calcaneal tumour is made radiologically. Thus, an X-ray is the first choice for detection of the lesion, followed by auxiliary CT, MRI and BS examinations $(1,2,123)$. A well-defined osteolytic area with a sclerotic margin is primarily presented in benign tumour types. For malignant tumour types, a moth-eaten or permeative pattern is a typical characteristic (1). Histological examination is the gold standard for the diagnosis of a majority of calcaneal tumour types (2). The final diagnosis entails a combination of the symptomatology, imageology and histopathology. It is imperative not only to exclude other differential diagnoses but additionally to select a preferable therapeutic regimen and prognosticate the disease outcome. The treatment of a calcaneal tumour varies depending on the Enneking system. Follow-up reports on the prognosis of patients with a calcaneal tumour are scarce. Due to the insufficient availability of studies on calcaneal tumour types, further studies should shed light on a substantially more detailed standard for the diagnosis and treatment of the primary calcaneal tumour.

\section{Acknowledgements}

Not applicable.

\section{Funding}

The design of the study was supported by National Natural Science Foundation of China (grant no. 81573734).

\section{Availability of data and materials}

Not applicable.

\section{Authors' contributions}

MS and SW were responsible for the conception and design of the study. LY was responsible for drafting, revising the 
initial manuscript. JZ, JC and WW contributed to the collection, analysis and interpretation of data. ML and XW revised and expanded the manuscript. SW was responsible for the study. All authors read and approved the final manuscript.

\section{Ethics approval and consent to participate}

Not applicable.

\section{Consent for publication}

Not applicable.

\section{Competing interests}

The authors declare that they have no competing interests.

\section{References}

1. Kilgore WB and Parrish WM: Calcaneal tumors and tumor-like conditions. Foot Ankle Clin 10: 541-565, 2005.

2. Young PS, Bell SW, MacDuff EM and Mahendra A: Primary osseous tumors of the hindfoot: Why the delay in diagnosis and should we be concerned? Clin Orthop Relat Res 471: 871-877, 2013.

3. Hanna SJ, Dasic D and Floyd A: Simple bone cysts of the calcaneus: A report of five cases and a review of the literature. Foot Ankle Int 25: 680-684, 2004.

4. Polat O, Sağlik Y, Adiguzel HE, Arikan M and Yildiz HY: Our clinical experience on calcaneal bone cysts: 36 cysts in 33 patients. Arch Orthop Trauma Surg 129: 1489-1494, 2009.

5. Takada J, Hoshi M, Oebisu N, Ieguchi M, Kakehashi A, Wanibuchi $\mathrm{H}$ and Nakamura $\mathrm{H}$ : A comparative study of clinicopathological features between simple bone cysts of the calcaneus and the long bone. Foot Ankle Int 35: 374-382, 2014.

6. Park IH, Micic ID and Jeon IH: A study of 23 unicameral bone cysts of the calcaneus: Open chip allogeneic bone graft versus percutaneous injection of bone powder with autogenous bone marrow. Foot Ankle Int 29: 164-170, 2008.

7. Lenze U, Stolberg-Stolberg J, Pohlig F, Lenze F, von Eisenhart-Rothe R, Rechl H and Toepfer A: Unicameral bone cyst in the calcaneus of mirror image twins. J Foot Ankle Surg 54: 754-757, 2015.

8. Yildirim C, Akmaz I, Sahin O and Keklikci K: Simple calcaneal bone cysts: A pilot study comparing open versus endoscopic curettage and grafting. J Bone Joint Surg Br 93: 1626-1631, 2011.

9. Chen L, Zhang G, Li S, Wu Z, Yuan W and Hong J: Percutaneous treatment of calcaneus fractures associated with underlying bone cysts. Foot Ankle Int 33: 424-429, 2012.

10. Levy DM, Gross CE and Garras DN: Treatment of unicameral bone cysts of the calcaneus: A systematic review. J Foot Ankle Surg 54: 652-656, 2015.

11. Rhee JH, Lewis RB and Murphey MD: Primary osseous tumors of the foot and ankle. Magn Reson Imaging Clin N Am 16: 71-91, 2008.

12. Enneking WF, Spanier SS and Goodman MA: A system for the surgical staging of musculoskeletal sarcoma. Clin Orthop Relat Res 153: 106-120, 1980.

13. Gallagher TA, Lim-Dunham JE and Vade A: CT findings of a unicameral calcaneal bone cyst containing a fluid-fluid level. Comput Med Imaging Graph 31: 111-113, 2007.

14. Dormans JP and Dormans NJ: Use of percutaneous intramedullary decompression and medical-grade calcium sulfate pellets for treatment of unicameral bone cysts of the calcaneus in children. Orthopedics 27 (Suppl 1): S137-S139, 2004.

15. Abdel-Wanis ME, Tsuchiya H, Uehara K and Tomita K: Minimal curettage, multiple drilling, and continuous decompression through a cannulated screw for treatment of calcaneal simple bone cysts in children. J Pediatr Orthop 22: 540-543, 2002

16. Elias I, Zoga AC, Raikin SM, Schweitzer ME and Morrison WB Incidence and morphologic characteristics of benign calcaneal cystic lesions on MRI. Foot Ankle Int 28: 707-714, 2007.
17. Altermatt S, Schwöbel M and Pochon JP: Operative treatment of solitary bone cysts with tricalcium phosphate ceramic. Eur J Pediatr Surg 2: 180-182, 1992.

18. Babazadeh S, Broadhead ML, Schlicht SM, Powell GJ and Tymms GM: Pathologic fracture of a calcaneal aneurysmal bone cyst. J Foot Ankle Surg 50: 727-732, 2011.

19. Kaplanoğlu V, Ciliz DS, Kaplanoğlu H and Elverici E: Aneurysmal bone cyst of the calcaneus. J Clin Imaging Sci 4: 60, 2014.

20. Kuna S and Gudena R: 'Soap bubble' in the calcaneus. CMAJ 183: $1171,2011$.

21. Parashari UC, Khanduri S, Upadhyay D, Bhadury S and Singhal S: Radiologic and pathologic correlation of aneurysmal bone cysts at unusual sites. J Cancer Res Ther 8: 103-105, 2012.

22. Malik A, Deb P, Mani NS and D'Souza J: Aneurysmal bone cyst of the calcaneum: An expansile locally destructive lesion. J Cancer Res Ther 6: 570-572, 2010.

23. Tequabo Y, Admasie D, Gebeyaw A and Yusuf N: Aneurysmal bone cyst of the calcaneus. Ethiop Med J 50: 271-273, 2012.

24. Carpenter B and Motley T: Bone matrix therapy for aneurysmal bone cysts. J Am Podiatr Med Assoc 95: 394-397, 2005.

25. Mohan, Susanta and Shivakumar: An unusual case of aneurismal bone cyst of the calcaneus: A case report. J Evolution of Medical and Dental Sciences 3: 4363-4366, 2014.

26. Aratake M, Shigeyuki M, Atsushi H, Takeuchi R and Saito T: Case of juxta-articular osteoid osteoma of calcaneus mimicking arthritis. J Foot Ankle Surg 51: 237-240, 2012.

27. Zouari L, Bousson V, Hamzé B, Roulot E, Roqueplan F and Laredo JD: CT-guided percutaneous laser photocoagulation of osteoid osteomas of the hands and feet. Eur Radiol 18: 2635-2641, 2008.

28. Pogliacomi F and Vaienti E: Misdiagnosed iuxta-articular osteoid osteoma of the calcaneus following an injury. Acta Biomed 74: 144-150, 2003

29. Okuda R, Kinoshita M, Morikawa J, Jotoku T, Shima H and Abe M: Tibialis spastic varus foot caused by osteoid osteoma of the calcaneus. Clin Orthop Relat Res: 149-152, 2003.

30. Lo AB, Chow AH, Wong WC, Hui JP and Yuen MK: Osteoid osteoma of the calcaneum: A small painful lesion causing confusing symptoms. Hong Kong Med J 18: 70-72, 2012.

31. Migues A, Velan O, Solari G, Pace G, Slullitel G and Araujo ES: Osteoid osteoma of the calcaneus: Percutaneous radiofrequency ablation. J Foot Ankle Surg 44: 469-472, 2005.

32. Sanhudo JA: Osteoid osteoma of the calcaneus mimicking os trigonum syndrome: A case report. Foot Ankle Int 27: 548-551, 2006.

33. Hamada T, Matsubara H, Kimura H, Aikawa T, Yoshida Y and Tsuchiya H: Intra-articular osteoid osteoma of the calcaneus: A case report and review. Radiol Case Rep 11: 212-216, 2016.

34. Daniilidis K, Martinelli N, Gosheger G, Hoell S, Henrichs M, Vogt B, Hardes J and Vieth V: Percutaneous CT-guided radio-frequency ablation of osteoid osteoma of the foot and ankle. Arch Orthop Trauma Surg 132: 1707-1710, 2012.

35. Wallace AN, Tomasian A, Chang RO and Jennings JW: Treatment of osteoid osteomas using a navigational bipolar radiofrequency ablation system. Cardiovasc Intervent Radiol 39: 768-772, 2016.

36. Hosalkar HS, Garg S, Moroz L, Pollack A and Dormans JP: The diagnostic accuracy of MRI versus CT imaging for osteoid osteoma in children. Clin Orthop Relat Res 433: 171-177, 2005.

37. Nogier A, De Pinieux G, Hottya G and Anract P: Case reports: Enlargement of a calcaneal osteochondroma after skeletal maturity. Clin Orthop Relat Res 447: 260-266, 2006.

38. Koplay M, Toker S, Sahin L and Kilincoglu V: A calcaneal osteochondroma with recurrence in a skeletally mature patient: A case report. Cases J 2: 7013, 2009.

39. Kumar R, Anjana and Kundan M: Retrocalcaneal Bursitis due to Rare Calcaneal Osteochondroma in Adult Male: Excision and Outcome. J Orthop Case Rep 6: 16-19, 2016.

40. Jung HG, Carag JA, Park JY, Bae EJ, Lim SD and Kim HS: Osteochondroma of the calcaneus presenting as Haglund's deformity. Foot Ankle Surg 17: e20-e22, 2011.

41. Blitz NM and Lopez KT: Giant solitary osteochondroma of the inferior medial calcaneal tubercle: A case report and review of the literature. J Foot Ankle Surg 47: 206-212, 2008.

42. Akmaz I, Arpacioğlu MO, Pehlivan O, Solakoglu C, Kiral A, Kaplan H and Rodop O: Calcaneal osteochondroma. J Am Podiatr Med Assoc 94: 409-411, 2004.

43. Sella EJ and Chrostowski JH: Calcaneal osteochondromas. Orthopedics 18: 573-574, 1995. 
44. Nakanishi H, Araki N, Mukai K, Ohno H, Matsui Y and Hosoya T: Soft-tissue osteochondroma in the calcaneal pad: A case report. J Foot Ankle Surg 40: 396-400, 2001.

45. Murphey MD, Choi JJ, Kransdorf MJ, Flemming DJ and Gannon FH: Imaging of osteochondroma: Variants and complications with radiologic-pathologic correlation. Radiographics 20 : 1407-1434, 2000.

46. Davila JA, Amrami KK, Sundaram M, Adkins MC and Unni KK Chondroblastoma of the hands and feet. Skeletal Radiol 33 582-587, 2004.

47. Guedes A, Barreto B, Soares Barreto LG, Athanazio DA and Athanazio PR: Calcaneal chondroblastoma with secondary aneurysmal bone cyst: A case report. J Foot Ankle Surg 49: 298 , 2010.

48. Dutt L, Schade VL and Manoso MW: Calcaneal chondroblastoma with pathologic fracture and recurrence. J Foot Ankle Surg 54: 258-267, 2015.

49. Otsuka T, Kobayashi M, Yonezawa M, Kamiyama F, Matsushita Y and Matsui N: Treatment of chondroblastoma of the calcaneus with a secondary aneurysmal bone cyst using endoscopic curettage without bone grafting. Arthroscopy 18: 430-435, 2002.

50. Ly JQ, LaGatta LM and Beall DP: Calcaneal chondroblastoma with secondary aneurysmal bone cyst. AJR Am J Roentgenol 182: 130, 2004.

51. Liu D, Xiao P, Gao Z, Xue L, Wang L, Liu Y and Han A: Chondroblastoma with adamantinoma differentiation of the calcaneus. Pathology 43: 174-176, 2011.

52. Bertram C, Popken F and Rutt J: Intraosseous lipoma of the calcaneus. Langenbecks Arch Surg 386: 313-317, 2001.

53. Ulucay C, Altintas F, Ozkan NK, Inan M and Ugutmen E: Surgical treatment for calcaneal intraosseous lipomas. Foot (Edinb) 19: 93-97, 2009.

54. Narang S and Gangopadhyay M: Calcaneal intraosseous lipoma: A case report and review of the literature. J Foot Ankle Surg 50: 216-220, 2011

55. Weinfeld GD, Yu GV and Good JJ: Intraosseous lipoma of the calcaneus: A review and report of four cases. J Foot Ankle Surg 41: 398-411, 2002

56. Pappas AJ, Haffner KE and Mendicino SS: An intraosseous lipoma of the calcaneus: A case report. J Foot Ankle Surg 53: 638-642, 2014.

57. Hassani M, Gharehdaghi M, Khooei AR, Ghodsi E and Nazarzadeh H: Bilateral intraosseous tumor of the calcaneus with imaging-pathologic discordance a case report and literatures review. Arch Bone Jt Surg 2: 238-242, 2014.

58. Aumar DK, Dadjo YB and Chagar B: Intraosseous lipoma of the calcaneus: Report of a case and review of the literature. J Foot Ankle Surg 52: 360-363, 2013.

59. Futani H, Fukunaga S, Nishio S, Yagi M and Yoshiya S: Successful treatment of bilateral calcaneal intraosseous lipomas using endoscopically assisted tumor resection. Anticancer Res 27: 4311-4314, 2007.

60. Muramatsu K, Tominaga Y, Hashimoto T and Taguchi T: Symptomatic intraosseous lipoma in the calcaneus. Anticancer Res 34: 963-966, 2014.

61. Karthik K and Aarthi S: Intraosseous lipoma of the calcaneus mimicking plantar fascitis. Foot Ankle Surg 17: e25-e27, 2011

62. Efrimescu CI, Bandorf N, Maxwell N and Niall D: A rare case of calcaneal tumour in a young adult. BMJ Case Rep 2012: pii: bcr0220125896, 2012.

63. Murphey MD, Carroll JF, Flemming DJ, Pope TL, Gannon FH and Kransdorf MJ.: From the archives of the AFIP: Benign musculoskeletal lipomatous lesions. Radiographics 24: 1433-1466, 2004.

64. Minhas MS, Khan KM and Muzzammil M: Giant cell tumour of foot bones-25 years experience in a tertiary care hospital. J Pak Med Assoc 65 (Suppl 3): S67-S71, 2015

65. Kamal AF, Waryudi A, Effendi Z and Kodrat E: Management of aggressive giant cell tumor of calcaneal bone: A case report. Int J Surg Case Rep 28: 176-181, 2016.

66. Ozer D, Er T, Aycan OE, Oke R, Coskun M and Kabukcuoglu YS May bone cement be used to treat benign aggressive bone tumors of the feet with confidence? Foot(Edinb) 24: 1-5, 2014

67. OConnor P, Gibbon W and Stone M: Sonographic demonstration of fluid-fluid levels in an aneurysmal bone cyst secondary to a giant cell tumour of the calcaneus. Clinical Radiology Extra 59: 43-47, 2004.

68. Dhillon MS, Prabhudev Prasad A, Virk MS and Aggarwal S: Multicentric giant cell tumor involving the same foot: A case report and review of literature. Indian J Orthop 41: 154-157, 2007
69. Yale JF and Kaplan JA: Aneurysmal bone cyst arising from a giant cell tumor of the calcaneus. J Am Podiatr Med Assoc 85: 708-709, 1995.

70. Joshi A, Shahi R, Singh S, Chand P and K C BR: Calcaneal myxoid chondrosarcoma: A rare case. JNMA J Nepal Med Assoc 52: 130-132, 2012.

71. Roberts EJ, Meier MJ, Hild G, Masadeh S, Hardy M and Bakotic BW: Chondromyxoid fibroma of the calcaneus: Two case reports and literature review. J Foot Ankle Surg 52: 643-649, 2013.

72. Jamshidi K, Mazhar FN and Yahyazadeh H: Chondromyxoid fibroma of calcaneus. Foot Ankle Surg 19: 48-52, 2013.

73. Ebrahimzadeh MH and Dallouei SR: Chondromyxoid fibroma of the calcaneus. J Am Podiatr Med Assoc 97: 223-224, 2007.

74. Budny AM, Ismail A and Osher L: Chondromyxoid Fibroma. J Foot Ankle Surg 47: 153-159, 2008.

75. Raatikainen TK, Kaarela OI, Holmström T, Kyllönen AP, Teerikangas HE and Waris TH: Desmoplastic fibroma of the calcaneus treated with a microvascular bone graft case report. Scand J Plast Reconstr Surg Hand Surg 33: 111-116, 1999.

76. Yu JS, Lawrence S, Pathria M, Resnick D and Haghighi P: Desmoplastic fibroma of the calcaneus. Skeletal Radiol 24: 451-454, 1995.

77. Miyayama H, Sakamoto K, Ide M, Ise K, Hirota K, Yasunaga T and Ishihara A: Aggressive osteoblastoma of the calcaneus. Cancer 71: 346-353, 1993.

78. Schujman O: Benign osteoblastoma of the calcaneus. Curr Orthop Prac 197, 1977.

79. Mestdagh C, Forgeois $\mathrm{P}$ and LecomteHoucke M: A rare entity: The calcaneus intraosseous ganglion Revue de Chirurgie Orthopedique and Reparatrice de l'Appareil Moteur 83: 274-277, 1997.

80. Murff R and Ashry HR: Intraosseous ganglia of the foot. J Foot Ankle Surg 33: 396-401, 1994.

81. Tadashi H, Takanori H and Howard D: Epithelioid fibrous histiocytoma of bone. Int J Surg Pathol 3: 43-48, 1995.

82. Keskinbora M,Köse O, Karslioglu Y, Demiralp B and Basbozkurt M: Another cystic lesion in the calcaneus: Benign fibrous histiocytoma of bone. J Am Podiatr Med Assoc 103: 141-144, 2013.

83. Kinberg P: Xanthoma of a calcaneus. J Foot Ankle Surg 37: 531-534, 1998

84. Ahmed G, Al Dosari M, El-Mahi M and Abolfotouh SM: Primary xanthoma of calcaneus bone: Case report. Int J Surg Case Rep 5: 699-702, 2014.

85. Yamamoto T, Kawamoto T, Marui T, Akisue T, Hitora T, Nagira K, Yoshiya S and Kurosaka M: Multimodality imaging features of primary xanthoma of the calcaneus. Skeletal Radiol 32: 367-370, 2003

86. Kapukaya A, Arslan H, Ozkul E and Mizrak B: Primary xanthofibroma in the calcaneus: A case report. Acta Orthop Traumatol Turc 45: 203-207, 2011.

87. Hakozaki M, Tajino T, Watanabe K, Yamada H, Kikuchi S, Hojo H, Ishida T and Konno S: Intraosseous spindle cell hemangioma of the calcaneus: A case report and review of the literature. Ann Diagn Pathol 16: 369-373, 2012.

88. Taslakian B, Issa G, Saab R, Jabbour MN and Khoury NJ: Calcaneal osteosarcoma: A rare cause of heel pain in the paediatric population. BMJ Case Rep 2013, 2013

89. Choong PF, Qureshi AA, Sim FH and Unni KK: Osteosarcoma of the foot: A review of 52 patients at the mayo clinic. Acta Orthop Scand 70: 361-364, 1999.

90. Rahbar M and Mardanpour K: Calcaneal osteosarcoma; a case report. Iranian J Med Sci 33: 121-123, 2008.

91. Chou LB, Malawer MM, Kollender Y and Wellborn CC: Prosthetic replacement for intramedullary calcaneal osteosarcoma: A case report. Foot Ankle Int 19: 411-415, 1998.

92. Leithner A, Bodo K, Scheipl S, Radl R, Kastner N and Windhager R: Two cases of calcaneal osteosarcomas presenting as aneurysmal bone cysts. Foot Ankle Int 25: 815-818, 2004

93. Chou LB and Malawer MM: Osteosarcoma of the calcaneus treated with prosthetic replacement with twelve years of followup: A case report. Foot Ankle Int 28: 841-844, 2007.

94. Tsuji Y, Kusuzaki K, Kanemitsu K, Matsumoto T, Ishikawa Y and Hirasawa Y: Calcaneal osteosarcoma associated with Werner syndrome. J Bone Joint Surg Am 82: 1308-1313, 2000.

95. Mulligan ME and Kransdorf MJ: Sequestra in primary lymphoma of bone: Prevalence and radiologic features. AJR Am J Roentgenol 160: 1245-1248, 1993.

96. Jamshidi K and Ahangar AF: Primary lymphoma of the calcaneus: A Case Report. Shafa Ortho J 3: 1-4, 2016. 
97. Niemczyk M, Babiak I, Wyzgal J, Pykalo R and Paczek L: Primary T-cell lymphoma of the calcaneus in the kidney transplant recipient. Nephrol Dial Transplant 22: 1475-1476, 2007.

98. Blume P, Charlot-Hicks F and Mohammed S: Case report and review of primary bone diffuse large B-cell lymphoma involving the calcaneus. J Foot Ankle Surg 52: 666-672, 2013.

99. White LM, Siegel S, Shin SS, Weisman MH and Sartoris DJ: Primary lymphoma of the calcaneus. Skeletal Radiol 25: 775-778, 1996.

100. Skorman SE and Martin R: Primary lymphoma of the calcaneus with recurrence in the distal tibia: A case report. J Foot Ankle Surg 38: 278-282, 1999.

101. Singh DP, Dhillon MS, Sur RK, Sharma SC and Radotra BD: Primary lymphoma of the bones of the foot: Management of two cases. Foot Ankle 11: 314-316, 1991.

102. Ogose A, Unni KK, Swee RG, May GK, Rowland CM and Sim FH: Chondrosarcoma of small bones of the hands and feet. Cancer 80: 50-59, 1997.

103. de Moraes FB, Linhares ND, de Souza Domingues PM, Warzocha VN and Soares JM: Calcaneal chondrosarcoma: A case report. Rev Bras Ortop 49: 409-413, 2014.

104. Suresh Babu S, Sudhakar G, Kiran KR, Suresh Babu TV and Sridevi MU: Calcaneal chondrosarcoma: A case report. Foot (Edinb) 23: 166-168, 2013

105. Nagmani S, Rakesh J, Aditya A, Sandeep P, Arjun RH and Debasis G: Clear cell chondrosarcoma calcaneum-a case report and review of literature. Foot (Edinb) 25: 36-40, 2015.

106. Kwon JW, Choi JA, Kwack KS, Oh JH, Chung JH and Kang HS: Myxoid chondrosarcoma in the calcaneus: A case report with MR imaging findings. Skeletal Radiol 36 (Suppl 1): S82-S85, 2007.

107. Wagner A, Venbrocks RA and Fuhrmann RA: Chondrosarcoma of the calcaneus: Amputation or resection with limb preservation: A case report. Foot Ankle Int 28: 1090-1094, 2007.

108. Casadei R, Magnani M, Biagini R and Mercuri M: Prognostic factors in ewing's sarcoma of the foot. Clin Orthop Relat Res 420: 230-238, 2004.

109. Tiwari AK, Sisodia Y and Gautam Y: Ewing s sarcoma of the calcaneus bone. Sri Lanka J Surg 32: 4-5, 2014.

110. Agarwal N and Sabir AB: Ewing's sarcoma of the calcaneus with metastases to the tibia and fibula. Acta Orthop Belg 74: 270-272, 2008.

111. Jalal H, Belhadj Z, Enneddam H, Madhar M, Fikry T, Essadki O and Ousehal A: Contribution of magnetic resonance imaging in the diagnosis of talus skip metastases of Ewing's sarcoma of the calcaneus in a child: A case report. J Med Case Rep 5: 451, 2011.

112. Traki L, Rkain H, Aktaou S, Raissouni H, Lazrak N, Benbouazza K and Hajjaj-Hassouni N: Sonography can be useful in diagnosis of ewing sarcoma of the calcaneus. J Ultrasound Med 30: 1439-1441, 2011.
113. Demiralp B, Erler K, Ozturan EK, Bek D, Ozdemir T and Kurt B: An uncommon presentation of malignant fibrous histiocytoma of the calcaneus. J Am Podiatr Med Assoc 97: 218-222, 2007.

114. Daibata M, Bandobashi K and Taguchi H: Calcaneus involvement by multiple myeloma. Am J Hematol 80: 311-312, 2005.

115. Rong Y, Sato K, Yamamura S, Sugiura H, Katagiri H and Iwata H: Malignant hemangioendothelioma of the left calcaneus associated with fever and hematological abnormalities. Skeletal Radiol 26: 64-66, 1997.

116. Goldenberg RR: Well Differentiated fibrosarcoma of the calcaneus: Report of a case treated by resection. J Bone Joint Surg 42: $1151-1155,1960$

117. Gahlot GP, Mridha AR, Nath D, Khan SA and Gamanagatti S: Intraosseous primary malignant peripheral nerve sheath tumor of the calcaneus: An unusual case and review of literature. Indian J Pathol Microbiol 58: 220-222, 2015.

118. Balaji GG, Arockiaraj JS, Roy AC and Deepak B: Primary epithelioid angiosarcoma of the calcaneum: A diagnostic dilemma. J Foot Ankle Surg 53: 239-242, 2014.

119. Madhuri V, Balakumar B, Walter NM, Prakash H, Dutt V and Chowdhurie L: Function after total calcanectomy for malignant tumor in a child: Is complex reconstruction necessary? J Foot Ankle Surg 51: 71-75, 2012.

120. Chandrasekar CR, Mohammed R, Rafalla AA and Grimer RJ: Adamantinoma of the calcaneum-a case report. Foot (Edinb) 19 58-61, 2009.

121. Oommen AT, Madhuri V and Walter NM: Review of foot tumors seen in a university tumor institute. Indian J Cancer 46: 234-236, 2009.

122. Ruggieri P, Angelini A, Jorge FD, Maraldi M and Giannini S: Review of foot tumors seen in a university tumor institute. J Foot Ankle Surg 53: 282-285, 2014.

123. Toepfer A, Lenze U and Harrasser N: Calcaneal ossoscopy. Arthrosc Tech 5: e627-e631, 2016.

124. Toepfer A, Lenze U, Gerdesmeyer L, Pohlig F and Harrasser N: Endoscopic resection and allografting for benign osteolytic lesions of the calcaneus. Springerplus 5: 427, 2016.

125. Dijkstra PU, Geertzen JH, Stewart R and van der Schans CP Phantom pain and risk factors: A multivariate analysis. J Pain Symptom Manage 24: 578-585, 2002.

126. Li J and Wang Z: Surgical treatment of malignant tumors of the calcaneus. J Am Podiatr Med Assoc 104: 71-76, 2014.

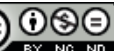

This work is licensed under a Creative Commons Attribution-NonCommercial-NoDerivatives 4.0 International (CC BY-NC-ND 4.0) License. 